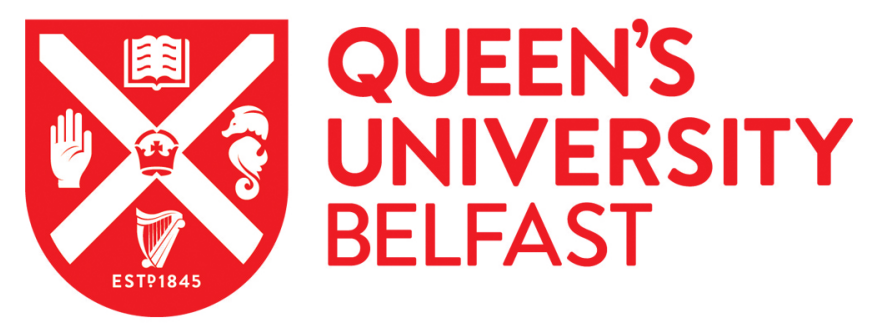

\title{
Porous Materials with Tunable Structure and Mechanical Properties via Templated Layer-by-Layer Assembly
}

Ziminska, M., Dunne, N., \& Hamilton, A. R. (2016). Porous Materials with Tunable Structure and Mechanical Properties via Templated Layer-by-Layer Assembly. ACS Applied Materials and Interfaces, 8(34), 21968-21973. https://doi.org/10.1021/acsami.6b07806

Published in:

ACS Applied Materials and Interfaces

Document Version:

Peer reviewed version

Queen's University Belfast - Research Portal:

Link to publication record in Queen's University Belfast Research Portal

Publisher rights

Copyright 2016 American Chemical Society.

This document is the unedited Author's version of a Submitted Work that was subsequently accepted for publication in ACS Applied Materials \& Interfaces.

To access the final edited and published work see:

http://pubs.acs.org/page/policy/articlesonrequest/index.html.

\section{General rights}

Copyright for the publications made accessible via the Queen's University Belfast Research Portal is retained by the author(s) and / or other copyright owners and it is a condition of accessing these publications that users recognise and abide by the legal requirements associated with these rights.

Take down policy

The Research Portal is Queen's institutional repository that provides access to Queen's research output. Every effort has been made to ensure that content in the Research Portal does not infringe any person's rights, or applicable UK laws. If you discover content in the Research Portal that you believe breaches copyright or violates any law, please contact openaccess@qub.ac.uk. 


\title{
Porous Materials with Tunable Structure and
}

\section{Mechanical Properties via Templated Layer-by-}

\section{Layer Assembly}

\author{
Monika Ziminska ${ }^{1}$, Nicholas Dunne ${ }^{2,3,4}$, Andrew R. Hamilton ${ }^{1, *}$
}

1. School of Mechanical \& Aerospace Engineering, Queen's University Belfast, Ashby Building, Stranmillis Road, Belfast, BT9 5AH, UK

2. Centre for Medical Engineering Research, School of Mechanical and Manufacturing Engineering, Dublin City University, Stokes Building, Collins Avenue, Dublin 9, Ireland

3. Trinity Centre for Bioengineering, Trinity Biomedical Sciences Institute, Trinity College Dublin, Dublin 2, Ireland

4. School of Pharmacy, Queen's University Belfast, 97 Lisburn Road, Belfast BT9 7BL, UK

Keywords: porous materials, layer-by-layer assembly, polymer nanoclay composites, mechanical properties, foams 
Abstract

The deposition of stiff and strong coatings onto porous templates offers a novel strategy for fabricating macroscale materials with controlled architectures at the micro- and nanoscale. Here, layer-by-layer assembly is utilized to fabricate nanocomposite-coated foams with highly customizable properties by depositing polymer-nanoclay coatings onto open-cell foam templates. The compressive mechanical behavior of these materials evolves in a predictable manner that is qualitatively captured by scaling laws for the mechanical properties of cellular materials. The observed and predicted properties span a remarkable range of density-stiffness space, extending from regions of very soft elastomer foams to very stiff, lightweight honeycomb and lattice materials.

Cellular materials, such as foams and honeycombs, have unique properties that are derived from their porous architecture, and depend on the base material, the relative density, and the morphology of the pores. ${ }^{1,2}$ Tailoring the mechanical properties of cellular materials is of interest for a variety of applications, including high-end packaging, high stiffness lightweight structures, and engineered tissue scaffolds. A variety of nanocomposite foams have been developed with the aim of creating stiff and strong lightweight structures. ${ }^{3}$ Adding nanometer-sized fillers such as clay nanoparticles to the foamed polymer matrix has the potential to mechanically reinforce and toughen polymer foams, ${ }^{4}$ but typically less than 10 weight $\%$ of clay nanoparticles can be homogenously dispersed into a polymer matrix. ${ }^{5}$ Further increases do not provide mechanical reinforcement and may even reduce the mechanical properties, ${ }^{1}$ making it difficult to obtain the 
high mechanical properties theoretically predicted for nanocomposites with high volume fractions of reinforcement. ${ }^{6}$

Layer-by-layer (LbL) assembly is a template-assisted method for fabricating multilayer films with nanometer-scale precision over thickness and composition. The process relies upon electrostatic interactions to drive the sequential adsorption of oppositely charged species onto a substrate, resulting in the formation of multilayer, nano-laminated coatings. ${ }^{7} \mathrm{LbL}$ assembly is capable of fabricating polymer nanocomposites with exceptionally high contents of welldispersed nano-reinforcement (approximately 50-70 volume \%), and with correspondingly high stiffness (tensile moduli as high as 15.7 to $125 \mathrm{GPa}$ ). ${ }^{6-10}$ The total thickness of an LbL assembled film is determined by the number of times an alternating deposition cycle of anionic and cationic species is repeated, ${ }^{11,12}$ but the nano- to microscale thickness per deposition cycle typical for LbL assembly is a major limitation of the technique and an impediment to utilizing the resulting materials for macroscale applications. ${ }^{13}$

LbL assembly of conformal coatings onto three-dimensional porous templates, such as foams, colloidal crystals, and hollow tubes has been implemented for a variety of applications, ${ }^{14-19}$ but these studies have largely focused on modifying the surfaces of these materials rather than altering the porous structure and bulk mechanical behavior. In this work, a polymer nanoclay composite coating is deposited onto open-cell foam templates using LbL assembly, emulating a general strategy that is used to produce porous materials from thin films. ${ }^{20}$ The structural and physical properties, as well as the mechanical behavior of the resulting nanocomposite-coated foams are characterized and the relationship between mechanical properties and the change in porous structure is qualitatively captured by scaling laws for open-cell foams. This approach offers a pioneering strategy for utilizing the unique properties of nano- to microscale LbL 
assembled materials to create bulk materials for macroscale applications. The nanocompositecoated foams fabricated in this study span a wide range of the material-property space, and the fabrication strategy offers a general approach for manufacturing materials with predicted properties spanning several orders of magnitude and that are suitable for anticipated applications including functional tissue engineered bone scaffold and lightweight structures.

Nanocomposite-coated foams were prepared using high porosity (approx. 98\%), open-cell polyurethane (PU) foams as templates for LbL assembly. LbL assembly was conducted in a closed chamber, through which the alternating flow of electrolyte solutions was controlled using a custom-built apparatus. A nanocomposite coating consisting of polyethyleneimine (PEI), polyacrylic acid (PAA), and bentonite nanoclay was utilized for the large thickness per PEI/PAA/PEI/nanoclay quadlayer (approx. $1 \mu \mathrm{m}$ ) and high mechanical stiffness (elastic modulus, $E=15.7 \mathrm{GPa}$ ) reported by Podsiadlo et al. for a similar material system. ${ }^{8}$ After washing with $1 \mathrm{M} \mathrm{NaOH}$ solution and drying for $24 \mathrm{~h}$, foam templates were sequentially subjected to $1 \mathrm{wt} \%$ polycationic PEI solution with $\mathrm{pH} 10.5$ for $30 \mathrm{~s}, 1 \mathrm{wt} \%$ polyanionic PAA solution with $\mathrm{pH} 8$ for $30 \mathrm{~s}$, the same PEI solution for $30 \mathrm{~s}$, and $1 \mathrm{wt} \%$ anionic bentonite nanoclay solution with $\mathrm{pH} 10$ for $30 \mathrm{~s}$. The introduction of each electrolyte solution into the chamber was punctuated by a thorough rinse with deionized (DI) water to prevent intermingling of the oppositely charged solutions. The assembly of a single PEI/PAA/PEI/nanoclay quadlayer was repeated a total of five times before the foam specimen was removed and dried for $24 \mathrm{~h}$ under ambient conditions (approximately $23^{\circ} \mathrm{C}$ and $30 \%$ relative humidity). Additional quadlayers were applied by repeating this procedure until the desired total number of quadlayers was achieved. 
The morphologies of uncoated foam templates and nanocomposite-coated foams with coatings ranging from 10 to 60 quadlayers were investigated using scanning electron microscopy (SEM) to inspect cryo-fractured specimens. Figures 1a and b reveal the microstructure of the foam templates, the high level of interconnectivity in both uncoated (1a) and coated foams (1b), and the apparently uniform presence of the coating throughout the structure of coated foams. The tricuspid hypocycloidal cross-section of the foam struts (typical for open-cell foams) is evident in Figures 1c-e. Representative specimens coated with 10 and 60 quadlayers exhibit a conformal coating around the perimeter of the cross-sectioned struts, as shown in Figures 1d and e, respectively. The micrographs reveal the variation in thickness of the coatings around the perimeter of the foam struts. In Figure 1f, evidence of the stratified "brick-and-mortar" structure can be seen, which results from the alternating deposition of polymer and nanoclay. ${ }^{9}$ Volumetric reconstructions of uncoated and coated foams in Figures $1 \mathrm{~g}$-h, which were obtained from X-ray micro-focus computed tomography (microCT), provide further evidence of the uniform presence of the coating throughout the volume of the foam templates. 


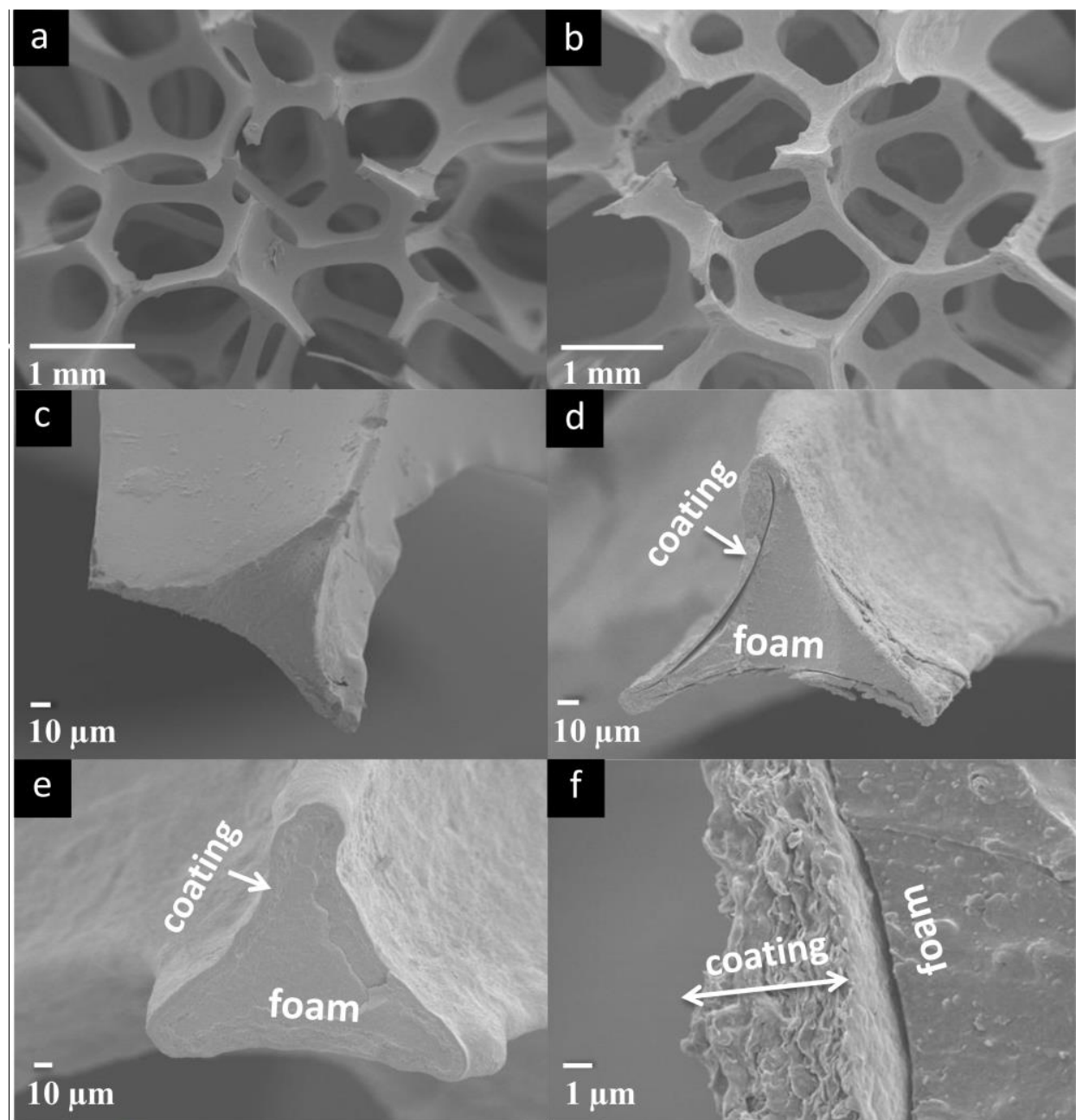

g

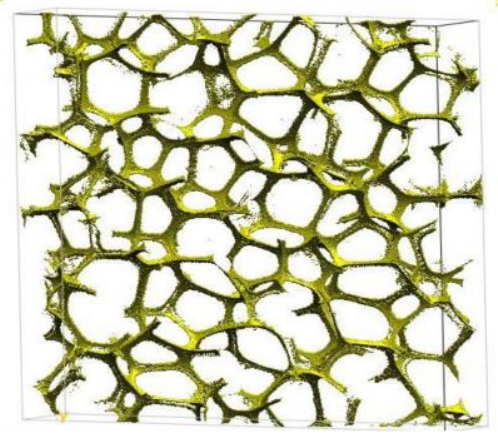

$\mathrm{h}$

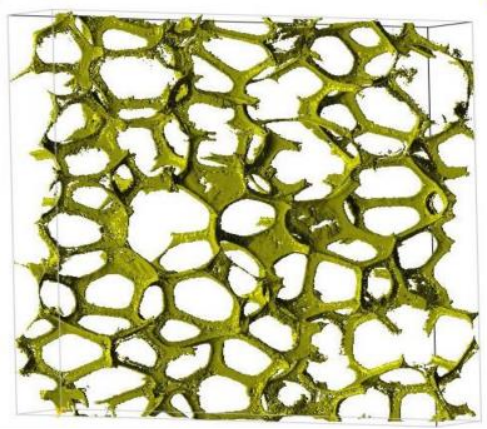

Figure 1. SEM micrographs of foams coated with (a) 0 (uncoated) and (b) 60 quadlayers at 25x magnification; (c) foams coated with 0 (uncoated), (d) 10 quadlayers, and (e) 60 quadlayers at 430x magnification; (f) and foam coated with 30 quadlayers at $6500 x$ magnification. Volumetric reconstructions of (g) uncoated foam and (h) foam coated with 60 quadlayers. Each rendered volume is approximately $9 \times 9 \times 1 \mathrm{~mm}$. 
Contrary to the extensive cracking reported by Podsiadlo et al. ${ }^{8}$ when a similar material system was assembled onto glass substrates, little evidence of damage was observed in the coatings on foams, except for localized cracking and areas of minor delamination from the foam template, as in Figure 1d, which are likely artefacts of the cryo-fracturing process. The lack of cracking can be explained by the lower stiffness of the PU foam substrate compared with the glass microscope slides used by Podsiadlo et al., which would reduce the residual stresses due to drying and shrinkage of the coating. ${ }^{21}$

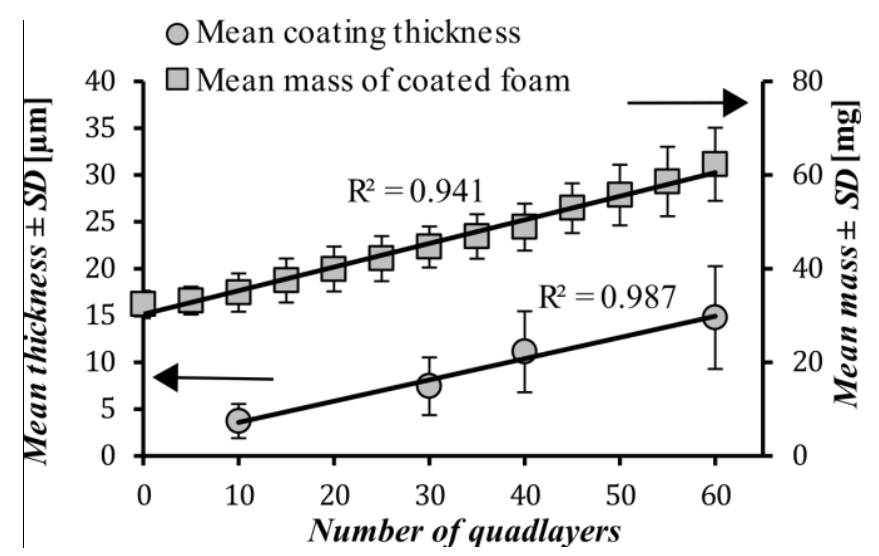

Figure 2. Nanocomposite-coated foam mass $(n=3)$ and coating thickness (measured from SEM micrographs) as functions of the number of quadlayers, with linear regressions and corresponding coefficients of determination $\left(\mathrm{R}^{2}\right)$. Error bars indicate one standard deviation from the mean values.

The mean thickness of the nanocomposite coatings presented in Figure 2 was calculated based on a minimum of seven SEM images taken at different locations within samples coated with 10,30,40, and 60 quadlayers of nanocomposite. The increase in thickness correlates strongly with the number of quadlayers deposited, with coefficient of determination $\mathrm{R}^{2}=0.987$. The thickness increased from $3.71 \pm 1.83 \mu \mathrm{m}$ for 10 quadlayers to $14.77 \pm 5.49 \mu \mathrm{m}$ for 60 
quadlayers $(p<0.05)$, indicating a mean thickness per quadlayer of $0.246 \mu \mathrm{m}$, which is consistent with that of similar material systems. ${ }^{8,15,22}$ The variability in coating thickness is consistent with the observations of Kim et al., ${ }^{22}$ who reported similar variations in the thickness of LbL-assembled coatings onto foam templates.

The consistent increase in the mass of nanocomposite-coated foams as a function of the number of quadlayers deposited is also shown in Figure 2. A linear regression fits the data well $\left(\mathrm{R}^{2}=0.941\right)$, and the slope indicates a mean mass per quadlayer of $0.499 \mathrm{mg}$. The mean mass after assembly of 60 quadlayers $(62.31 \pm 7.82 \mathrm{mg})$ was approximately double that of an uncoated foam $(32.37 \pm 2.91 \mathrm{mg})$. Control samples consisting of PU foams immersed in solutions of only PEI, PAA, nanoclay, or DI water for the period of time required to assemble a 60 quadlayer coating exhibited no significant change in mass $(p=0.872)$.

Two of the most important parameters characterizing the cellular structure and properties of foams are strut thickness and cell size. These parameters were measured from SEM images and from microCT data for both uncoated foams and foams coated with 60 quadlayers, and are presented in Table 1. The difference in the mean strut thickness for coated and uncoated foams is $37 \pm 18 \mu \mathrm{m}$ based on SEM data, or $19 \pm 2 \mu \mathrm{m}$ based on microCT data, both of which are consistent with twice the mean coating thickness of $14.77 \pm 5.49 \mu \mathrm{m}$ presented in Figure 2 for 60 quadlayer coatings. The smaller coating thickness implied by the microCT data can be explained by the lower resolution of this imaging technique, ${ }^{23}$ and by the two- vs. three-dimensional nature of these datasets. The difference in the mean cell size for coated and uncoated foams is difficult to compare due to the large variability of this parameter within the uncoated foam templates, as indicated by the large standard deviations in Table 1 . The porosity measured using microCT 
decreased from $98.8 \%$ for uncoated foam templates to $96.6 \%$ for foams coated with 60 quadlayers, indicating the negligible effect of these coatings on the overall porosity of the foams.

Table 1. Mean microstructural parameters for uncoated foam templates and nanocompositecoated foams with 60 quadlayer coatings.

\begin{tabular}{lllll}
\hline & $\begin{array}{l}\text { 0 quadlayers } \\
\text { (uncoated) PU } \\
\text { foam }\end{array}$ & $\begin{array}{l}60 \text { quadlayers } \\
\text { coated PU } \\
\text { foam }\end{array}$ & $\begin{array}{l}\text { 0 quadlayers } \\
\text { (uncoated) PU } \\
\text { foam }\end{array}$ & $\begin{array}{l}\text { 60 quadlayers } \\
\text { coated PU } \\
\text { foam }\end{array}$ \\
& SEM & SEM & microCT & microCT \\
\hline $\begin{array}{llll}\text { Strut thickness [mm] } \\
\text { Cell size [mm] }\end{array}$ & $0.118 \pm 0.036$ & $0.155 \pm 0.018$ & $0.086 \pm 0.04$ & $0.105 \pm 0.042$ \\
Porosity [\%] & $0.774 \pm 0.239$ & $0.738 \pm 0.333$ & $0.874 \pm 0.419$ & $0.753 \pm 0.339$ \\
\hline
\end{tabular}

Compressive mechanical testing within the elastic range of the nanocomposite-coated foams was conducted after assembly of every 10 quadlayers. Representative stress-strain curves are presented in Figure 3a for foams with increasing numbers of quadlayers, and the elastic moduli corresponding to the linear region with the largest slope are shown in Figure $3 \mathrm{~b}$. Statistically significant increases in modulus were observed for coated foams with each number of quadlayers tested (i.e. 10, 20, 30, 40, 50, and 60 quadlayers). The mean compressive modulus directly correlates to the number of quadlayers deposited $(r=0.983)$. After deposition of 60 quadlayers a maximum mean compressive modulus of $2.48 \pm 0.312 \mathrm{MPa}$ was obtained. 

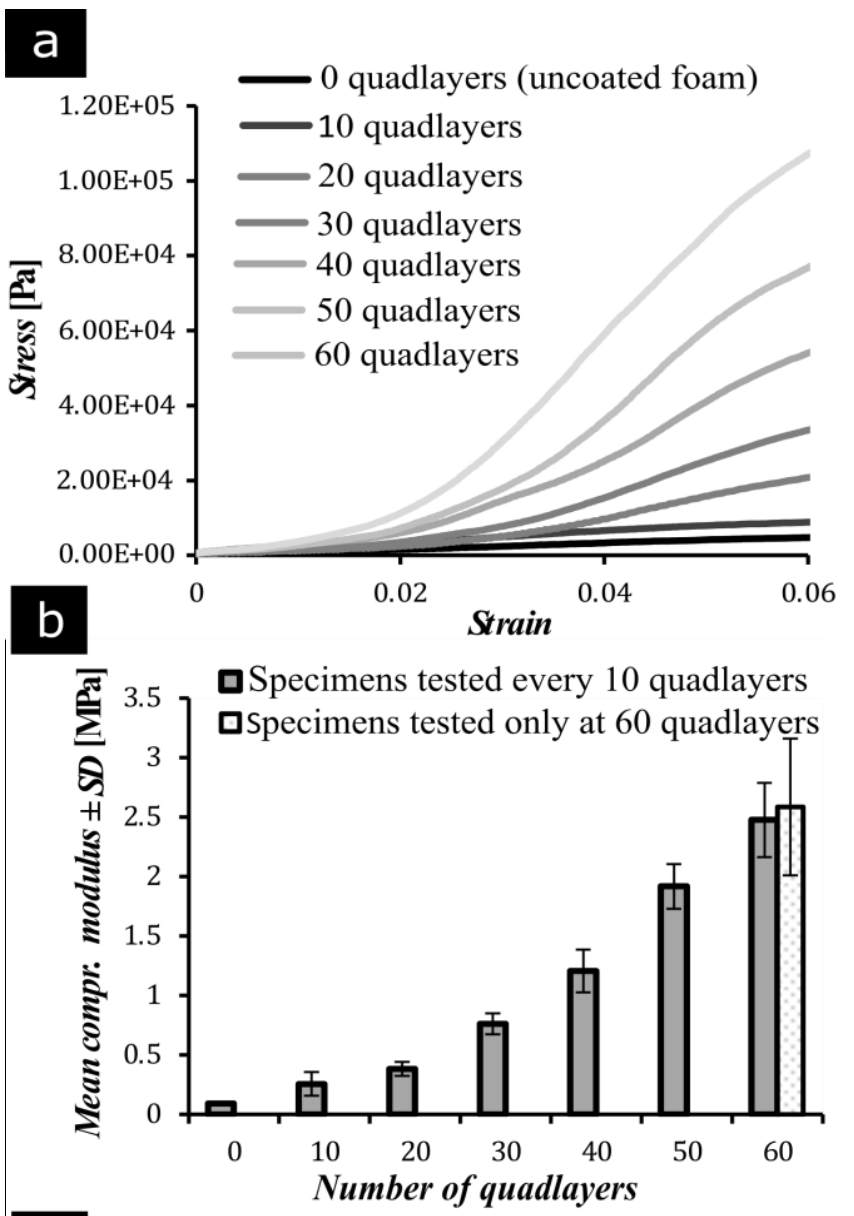

C

- Specimens tested only at 60 quadlayers

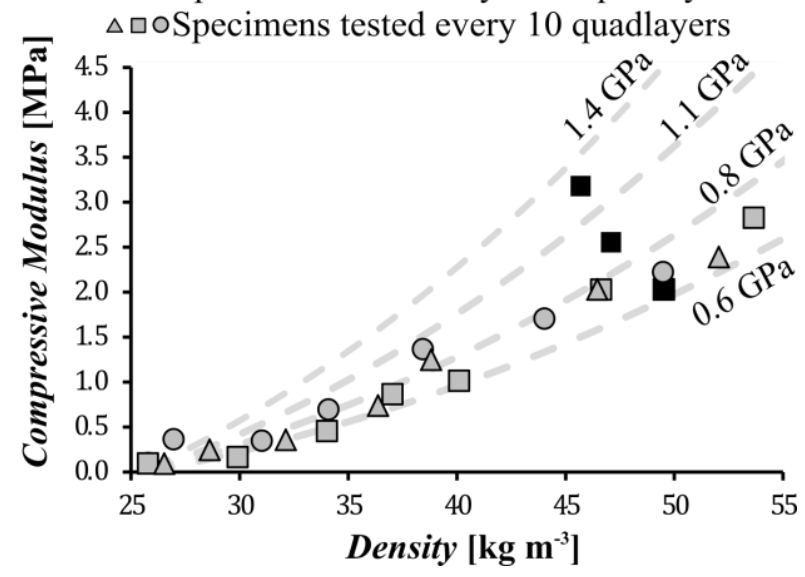

Figure 3. (a) Representative stress-strain curves for foams coated from 0 (uncoated) to 60 quadlayers. (b) Mean compressive elastic modulus of foams $(n=3)$ coated from 0 (uncoated) to 60 quadlayers. Error bars indicate one standard deviation from the mean values. (c) Compressive elastic modulus as a function of density for nanocomposite foams coated with up to 60 
quadlayers, with predicted trends (dashed lines) assuming different values of elastic modulus for the coating $\left(E_{\text {coating }}\right)$.

To confirm that the mechanical testing conducted at 10 quadlayer intervals did not affect the mechanical properties, additional nanocomposite-coated foam specimens were mechanically tested only after complete assembly of 60 quadlayer coatings. The results of these tests are included in Figure 3b, and indicate no statistically significant difference $(p=0.792)$ when compared with foams tested every 10 quadlayers. Control samples consisting of PU foams immersed only in solutions of DI water, PEI, PAA or bentonite nanoclay for the period of time required to assemble a 60 quadlayers coating exhibited no statistically significant change ( $p=$ $0.134)$ in compressive modulus.

Scaling laws for the physical and mechanical properties of foams based on a cubic unit cell with square struts at the edges have been well established. ${ }^{24}$ For a foam with a coating of uniform thickness $\Delta t$, surrounding a base material of thickness $t_{o}$, the total strut thickness can be expressed as $t=t_{o}+2 \Delta t$. Similarly, the cell size of a coated foam can be expressed as $l=l_{o}-$ $2 \Delta t$. Based on this unit cell geometry, the porosity $(\phi)$ and density $\left(\rho^{*}\right)$ of a coated foam can be expressed as:

$$
\phi=1-\left(\frac{\rho^{*}}{\rho_{\text {eff }}}\right) \cong 1-\left(\frac{t}{l}\right)^{2}=1-\left(\frac{t_{o}+2 \Delta t}{l_{o}-2 \Delta t}\right)^{2},
$$

where $\rho_{\text {eff }}$ is the effective density of the coated strut, which was calculated using the rule of mixtures for a strut composed of base and coating materials. Assuming that the coating material is much stiffer in flexure than the base material, the elastic modulus of a coated foam $\left(E^{*}\right)$ may be estimated using a modified scaling law for foams with hollow-struts, which neglects the contribution of the base material: ${ }^{25}$ 


$$
\frac{E^{*}}{E_{\text {coating }}} \cong \frac{t^{4}-t_{o}^{4}}{l^{4}}=\frac{\left(t_{o}+2 \Delta t\right)^{4}-t_{o}^{4}}{\left(l_{o}-2 \Delta t\right)^{4}}
$$

where $E_{\text {coating }}$ is the elastic modulus of the coating material.

Equations (1) and (2) were used to predict the density, porosity and compressive modulus of nanocomposite-coated foams for various coating thicknesses $(\Delta t)$. The dimensions of the base material $\left(t_{0}, l_{0}\right)$ were taken from the SEM data for uncoated foams in Table 1 , and the density of the base material was taken as $1200 \mathrm{~kg} \mathrm{~m}^{-3}$ for polyurethane. ${ }^{24}$ The density of the coating material was experimentally determined as $\rho_{\text {coating }}=343 \pm 21 \mathrm{~kg} \mathrm{~m}^{-3}$ (see SI for details). A range of values for the elastic modulus of the coating (from $E_{\text {coating }}=0.6 \mathrm{GPa}$ to $1.4 \mathrm{GPa}$ ) was used to predict the trend lines plotted in Figure 3c for coated foams, which bound the experimental data. The scaling laws in Equations (1) and (2) qualitatively capture the experimental data well, despite the simplified cubic unit cell geometry, with $\mathrm{R}^{2}=0.827$ for the trend line with $E_{\text {coating }}=$ $0.8 \mathrm{GPa}$.

The presumed range of elastic modulus for the coating material is consistent with tensile testing of the coating on a flexible carrier substrate, which yielded $E=0.601 \pm 0.518 \mathrm{GPa}$, and also with additional testing of the coating as detached stand-alone films, which yielded $E=1.67$ $\pm 1.06 \mathrm{GPa}$ (see SI for details). These moduli are lower than reported for similar material systems (15.7 GPa and 15.4 GPa for PEI/PAA materials with and without nanoclay, respectively) ${ }^{8,10}$ but are consistent with the much lower stiffness reported for PEI/PAA when produced under different LbL assembly conditions (approx. $0.225 \mathrm{GPa}$ ). ${ }^{26}$ The $\mathrm{pH}$ of solutions has been identified as a contributing factor affecting the degree of ionic crosslinking and interdiffusion of PEI/PAA, ${ }^{27}$ and is a likely contributor to the lower modulus obtained in this study. Humidity is also known to have a significant effect on the stiffness of multilayered materials ${ }^{28}$ 
and may also have contributed to the lower-than-expected moduli, and to the high standard deviations obtained for the modulus of the coating material.

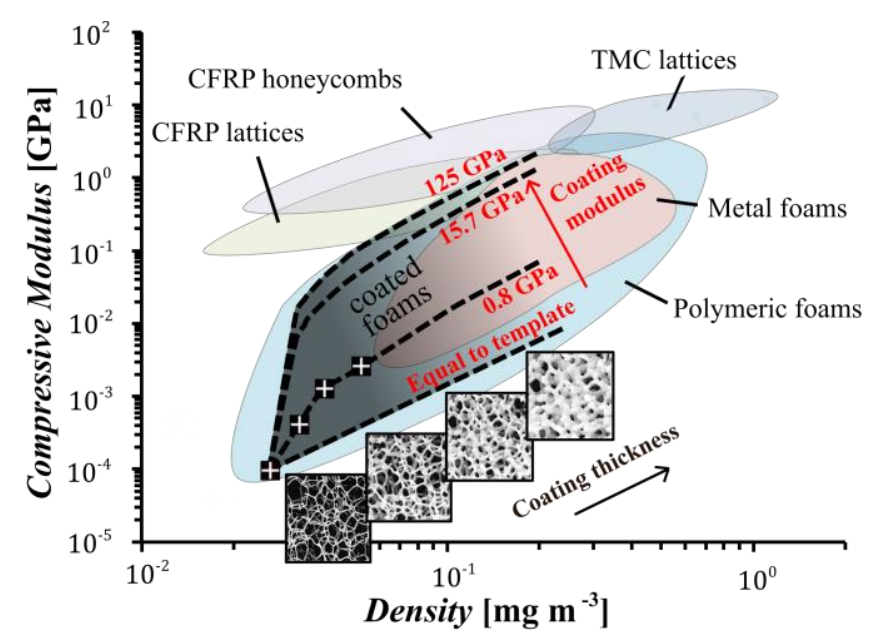

Figure 4. Ashby plot of compressive modulus and density. Experimental data (markers) and theoretical predictions (dashed lines) for nanocomposite-coated foams are included for coatings with elastic moduli ranging from 0.8 to $125 \mathrm{GPa}$. Common porous engineering materials, advanced lightweight honeycomb and lattice materials are included for comparison. The inset images illustrate the change in foam architecture with increasing coating thickness.

The elastic modulus of the nanocomposite-coated foams developed in this work is plotted as a function of density on the log-log plot in Figure 4, and compared with the properties of other porous cellular materials that are typically employed in engineering applications. The experimental results of this work cover a wide range of material-property space, overlapping the typical material-property space for polymer foams. The predicted trends are plotted as dashed lines, and can be extrapolated to project the impact of thicker coatings, which are within the range of properties for metal foams. Predicted trends based on the elastic moduli reported for similar PEI/PAA/nanoclay material systems $(E=15.7 \mathrm{GPa})$ and assuming the same density as 
the materials reported herein are also plotted in Figure 4. Refining the LbL assembly conditions in order to achieve coatings with these superior mechanical properties would enable fabrication of nanocomposite-coated foams that are competitive with the best (lightest and stiffest) polymer and metal foams. Further improvements are predicted for foams coated with polyvinyl alcohol (PVA) nanoclay composites, ${ }^{6}$ based on the reported elastic modulus of up to $E=125 \mathrm{GPa}$ and assuming $\rho=1700 \mathrm{~kg} \mathrm{~m}^{-3}$ (conservatively estimated using the rule of mixtures). Assembling these coatings onto anisotropic foam templates would result in moduli up to several times stiffer in one direction, ${ }^{29}$ which would make these materials competitive with the lightest and stiffest carbon-fiber reinforced polymer (CFRP) lattice and honeycomb materials. ${ }^{30}$ Appropriate thicknesses and/or combinations of coating materials would allow a vast range of properties for nanocomposite-coated foams, and enable the possibility to "dial in" specific properties for a particular application and fabricate an appropriate material accordingly.

In conclusion, LbL assembly was implemented to prepare nanocomposite-coated foams with uniform conformal coatings and controllable thickness. The structure and physical properties of the foams evolved in a regular and predictable manner, with strut thickness and mass increasing, and cell size and porosity decreasing as the coating thickness increased. Compressive testing revealed a rapid increase in the elastic modulus of the foams that spanned an order of magnitude. The changes in physical and mechanical properties were qualitatively captured by modified scaling laws for elastic modulus and density based on a simple cubic unit cell model of open-cell foams. Using these models to extrapolate this general fabrication strategy to different material systems produced via LbL assembly, a class of nanocomposite-coated foam materials was predicted that spans a remarkable range of property space extending from regions of very soft elastomer foams to very stiff, lightweight honeycomb and lattice materials. It is anticipated that 
these highly customizable materials with tunable physical and mechanical properties will find useful application as lightweight structures, or in development of tissue engineered bone scaffolds.

\section{ASSOCIATED CONTENT}

\section{Supporting Information}

Experimental procedure, scheme of the deposition process, mechanical testing of the coating.

This material is available free of charge via the Internet at http://pubs.acs.org.

\section{AUTHOR INFORMATION}

Corresponding Author

*E-mail: a.hamilton@qub.ac.uk

Funding Sources

The research leading to these results has received funding from the European Union Seventh Framework Programme (FP7/2007-2013) under grant agreement n ${ }^{\circ}$ [631079], awarded to ARH. MZ was supported by a Research Studentship from the Department for Employment and Learning, Northern Ireland.

Notes

The authors declare no competing financial interest.

\section{ACKNOWLEDGMENT}


The authors are grateful to Dr. James Nixon for his assistance with digital image correlation and Dr. Iwan Palmer for helpful suggestions regarding statistics.

\section{REFERENCES}

[1] Javni, I; Zhang, W.; Karajkov, V.; Divjakovic, V. Effect of Nano- and Micro-Silica Fillers on Polyurethane Foam Properties. J. Cell. Plast. 2002, 38, 229-239.

[2] Compton, B. G.; Lewis, J. A. 3D-Printing of Lightweight Cellular Composites. Adv. Mater. 2014, 26, 5930-5935.

[3] Saha, M. C.; Kabirb, Md. E.; Jeelanic, S. Enhancement in Thermal and Mechanical Properties of Polyurethane Foam Infused with Nanoparticles. J. Mater. Sci. Eng. A 2008, 479, 213-222.

[4] Lobos, J.; Velankar, S. How Much do Nanoparticle Fillers Improve the Modulus and Strength of Polymer Foams? J. Cell. Plast. 2014, 52, 57-88.

[5] Istrate, O.I.; Chen, B. Relative Modulus-Relative Density Relationships in Low Density Polymer-Clay Nanocomposite Foams. Soft Matter 2011, 7, 1840-1848.

[6] Podsiadlo, P.; Kaushik, A. K.; Arruda, E. M.; Waas, A. M.; Sup Shim, B.; Xu, J.; Nandivada, H.; Pumplin. B. G.; Lahann, J.; Ramamoorthy, A.; Kotov, N.A. Ultrastrong and Stiff Layered Polymer Nanocomposites. Science 2007, 318, 80-83.

[7] Priolo, M.A.; Gamboa, D.; Holder, K. M.; Grunlan, J.C. Super Gas Barrier of Transparent Polymer-Clay Multilayer Ultrathin Films. Nano Lett. 2010, 10, 4970-4974.

[8] Podsiadlo, P.; Michel, M.; Lee, J.; Verploegen, E.; Wong Shi Kam, N.; Ball, V.; Lee, J.; Qi, Y.; Hart, A.J.; Hammond, P. T.; Kotov, N. A. Exponential Growth of LBL Films with Incorporated Inorganic Sheets. Nano Lett. 2008, 8, 1762-1770.

[9] Tang, Z.; Kotov, N.A.; Magonov, K.; Ozturk, B. Nanostructured artificial nacre. Nat. Mater. 2003, 2, 413-418.

[10] Cho, C.; Wallace, K.L.; Hagen, D. A.; Stevens, B.; Regev, O.; Grunlan, J.C. Nanobrick Wall Multilayer Thin Films Grown Faster and Stronger Using Electrophoretic Deposition. Nanotechnology 2015, 26, 1-7.

[11] Laugel, N.; Betscha, C.; Winterhalter, M.; Voegel, J.-C.; Schaaf, P.; Ball, V. Relationship between the Growth Regime of Polyelectrolyte Multilayers and the Polyanion/Polycation Complexation Enthalpy. J. Phys. Chem. B 2006, 110, 19443-19449.

[12] Picart, C.; Mutterer, J. Richert, L.; Lou, Y.; Prestwich, G.D.; Schaaf, P.; Voegel, J.-C.; Lavelle, P. Molecular Basis for the Explanation of the Exponential Growth of Polyelectrolyte Multilayers. PNAS, 2002, 99, 12531-12535.

[13] Podsiadlo, P.; Arruda, E.M.; Kheng, E.; Waas, A.M.; Lee, J.; Critchley, K.; Qin, M.; Chuang, E.; Kaushik, A.K.; Kim, H.-S.; Qi, Y.; Noh, S.-T.; Kotov, N.A. LBL Assembled 
Laminates with Hierarchical Organization from Nano- to Microscale: High-Toughness Nanomaterials and Deformation Imaging. ACS Nano 2009, 3, 1564-1572.

[14] Kim, T.G.; Park, S.-H. ; Chung, H. Y.; Yang, D.-Y.; Park, T.G. Microstructured Scaffold Coated with Hydroxyapatite/Collagen Nanocomposite Multilayer for Enhanced Osteogenic Induction of Human Mesenchymal Stem Cells. J. Mater. Chem. 2010, 20, 8927-8933.

[15] Kim, Y.S.; Davis, R.; Cain, A. A.; Grunlan, J.C. Development of Layer-By-Layer Assembled Carbon Nanofiber-Filled Coatings to Reduce Polyurethane Foam Flammability. Polymer 2011, 52, 2847-2855.

[16] Kim, Y.; Li, Y.-C.; Pitts, W. M.; Werrel, M.; Davis, R. D. Rapid Growing Clay Coatings to Reduce the Fire Threat of Furniture. ACS Appl. Mater. Interfaces 2014, 6, 2146-2152.

[17] Andres, C. M.; Fox, M. L.; Kotov, N.A. Traversing Material Scales: Macroscale LBLAssembled Nanocomposites with Microscale Inverted Colloidal Crystal Architecture. Chem Mater. 2012, 24, 9-11.

[18] Lee, J.; Shanbhag, S.; Kotov, N. A. Inverted Colloidal Crystals as Three-Dimensional Microenvironments for Cellular Co-Cultures. J. Mater. Chem. 2006, 16, 3558-3564.

[19] Costa, R.; Mano, J. F. Polyelectrolyte Multilayered Assemblies in Biomedical Technologies. Chem. Soc. Rev. 2014, 43, 3453-3479.

[20] Schaedler, T. A.; Carter, W.B. Architected Cellular Materials. Annu. Rev. Mater. Res. 2016, 46, 187-210.

[21] Papin, M.; Spelt, J. in Adhesion Science and Engineering; Dillard, D.; Pocius, A., Eds.; Elsevier Science: Amsterdam, 2002; pp. 303-350.

[22] Kim, Y. S.; Harris, R.; Davis, R. Innovative Approach to Rapid Growth of Highly ClayFilled Coatings on Porous Polyurethane Foam. ACS Macro Lett. 2012, 1, 820-824.

[23] Fischer, F.; Lim, G. T.; Handge, U. A.; Altstadt, V. Numerical Simulation of Mechanical Properties of Cellular Materials Using Computed Tomography Analysis. J. Cell. Plast. 2009, 45, 441-460.

[24] Gibson, L. J.; Ashby, M. F. Cellular Solids. Structure and Properties, 2nd ed; Cambridge University Press: Cambridge, 1997, pp 175-234.

[25] Hagiwara, H.; Green, D. J. Elastic Behavior of Open-Cell Alumina. J. Am. Ceram. Soc. 1987, 70, 811-815.

[26] Mamedov A. A.; Kotov, N. A.; Prato, M.; Guildi, D. M.; Wicksted, J. P.; Hirsch, A. Molecular Design of Strong Single-Wall Carbon Nanotube/Polyelectrolyte Multilayer Composites. Nat. Mater. 2002, 1, 190-194.

[27] Kim, D.; Tzeng, P.; Barnett, K. J.; Yang, Y-H; Wilhite, B. A.; Grunlan, J. C. Highly SizeSelective Ionically Crosslinked Multilayer Polymer Films for Light Gas Separation. Adv. Mater. 2014, 26, 746-751.

[28] Nolte, A. J.; Treat, N. D.; Cohen, R. E.; Rubner, M. F. Effect of Relative Humidity on the Young's Modulus of Polyelectrolyte Multilayer Films and Related Nonionic Polymers. Macromolecules 2008, 41, 5793-5798 
[29] Huber, A. T.; Gibson, L. J. Anisotropy of foams. J. Mater. Sci. 1988, 23, 3031-3040.

[30] George, T.; Deshpande, V. S.; Wadley, H. N.G. Mechanical Response of Carbon Fiber Composite Sandwich Panels with Pyramidal Truss Cores. Composites, Part A 2013, 47, $31-40$.

Table of Contents/Abstract Graphic

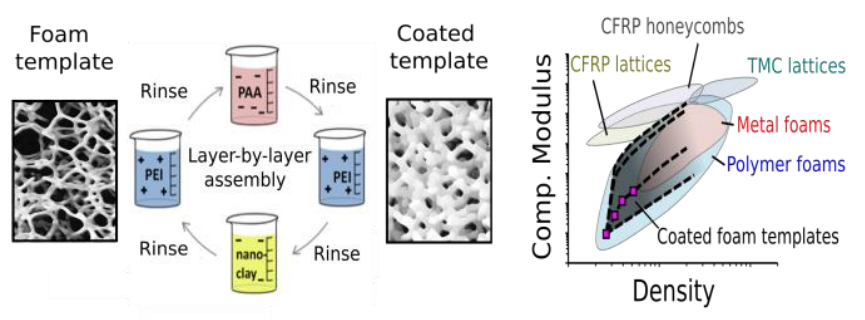




\title{
Supporting Information
}

\section{Porous Materials with Tunable Structure and}

\section{Mechanical Properties via Templated Layer-by-}

\section{Layer Assembly}

\author{
Monika Ziminska, ${ }^{1}$ Nicholas Dunne, ${ }^{2,3,4}$ Andrew R. Hamilton ${ }^{1, *}$
}

1. School of Mechanical \& Aerospace Engineering, Queen's University Belfast, Ashby Building, Stranmillis Road, Belfast, BT9 5AH, UK

2. Centre for Medical Engineering Research, School of Mechanical and Manufacturing Engineering, Dublin City University, Stokes Building, Collins Avenue, Dublin 9, Ireland

3. Trinity Centre for Bioengineering, Trinity Biomedical Sciences Institute, Trinity College Dublin, Dublin 2, Ireland

4. School of Pharmacy, Queen's University Belfast, 97 Lisburn Road, Belfast BT9 7BL, UK

\section{Corresponding Author}

*E-mail: a.hamilton@qub.ac.uk 
Fabrication of Nanocomposite-Coated Foams

Aqueous solutions of $35 \mathrm{wt} \% 100 \mathrm{kDa}$ polyacrylic acid (PAA), and $50 \mathrm{wt} \% 750 \mathrm{kDa}$ polyethyleneimine (PEI) were purchased from Sigma Aldrich, UK. 1 wt $\%$ PEI and PAA were prepared by dilution in deionized (DI) water under vigorous stirring for $12 \mathrm{~h}$. The $\mathrm{pH}$ of PEI was unchanged at 10.5 and the $\mathrm{pH}$ of PAA was adjusted to 8 by addition of sodium hydroxide $(\mathrm{NaOH})$. Hydrophilic bentonite nanoclay (Nanomer® clays, Nanocor®, Inc., USA) was purchased from Sigma Aldrich, UK, and an aqueous solution of $0.5 \mathrm{wt} \%$ prepared by dispersion in DI water and vigorous stirring for $24 \mathrm{~h}$.

Open-cell polyurethane (PU) foam with 30 pores per inch (PPI) was purchased from The Foam Shop Ltd, UK. Foam templates were cut using a punch stamp to obtain cylindrical specimens $12.7 \mathrm{~mm}$ in diameter and $10 \mathrm{~mm}$ in height.

Foam templates were submerged in a $1 \mathrm{M} \mathrm{NaOH}$ solution, repeatedly rinsed with DI water, and dried for $8 \mathrm{~h}$ prior to deposition. Foams were placed in a sealed chamber and subjected to solutions of the polycationic PEI for $30 \mathrm{~s}$, polyanionic PAA for $30 \mathrm{~s}$, PEI for $30 \mathrm{~s}$, and anionic nanoclay for 30 s, as summarized in Figure S1.

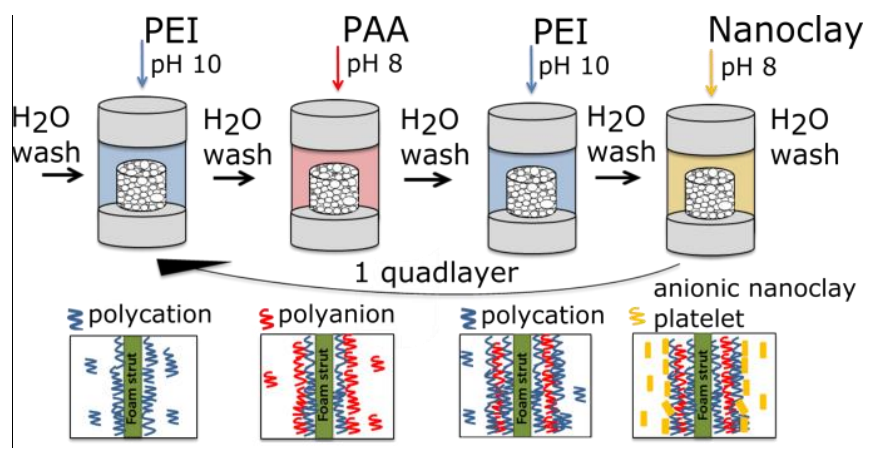

Figure S1. Schematic of LbL assembly of a single quadlayer onto porous foam template by controlled flow of electrolyte solutions through a closed chamber. 
The introduction of each solution was punctuated by three rinses with DI water, each with a total contact time of $30 \mathrm{~s}$. The full PEI/PAA/PEI/nanoclay deposition cycle was repeated five times, resulting in the deposition of five quadlayers. The coated foam was rinsed three times in DI water and dried for $24 \mathrm{~h}$ under ambient conditions (approximately $23^{\circ} \mathrm{C}$ and $30 \%$ relative humidity). Additional quadlayers were applied by repeating this procedure until the desired number of deposition cycles was reached. Four control samples were produced by submerging foam templates into only DI water, $1 \mathrm{wt} \% \mathrm{PEI}, 1 \mathrm{wt} \%$ PAA, or $0.5 \mathrm{wt} \%$ nanoclay solutions for the corresponding periods of contact time required to deposit a 60 quadlayer coating.

\section{Gravimetric Analysis}

Nanocomposite-coated foams and control specimens were weighed using an analytical balance (accurate to $0.0001 \mathrm{~g}$ ) after assembly of every five quadayers and drying for at least eight hours under ambient conditions (approximately $23^{\circ} \mathrm{C}$ and $30 \%$ relative humidity).

\section{Microscopy and Computed Tomography}

Scanning electron microscopy (SEM) was performed on a JEOL 6500 FEG SEM (Advanced Microbeam Inc., USA) with an operational voltage $3.0 \mathrm{kV}$. Prior to SEM, samples were cryofractured using liquid nitrogen and sputter coated with gold. The nanocomposite coating thickness was calculated based on 10 measurements from a minimum of seven different locations on each sample.

Volumetric imaging was performed using a $\mu \mathrm{CT} 40$ X-ray micro-focus computed tomography system (Scanco Medical, Switzerland) at a nominal resolution of $8 \mu \mathrm{m}$. Microstructural analysis was performed using reconstructed images segmented at an intensity of 20 . 
Mechanical Testing of Nanocomposite-Coated Foams

Quasi-static mechanical testing in compression was conducted using a TA-XT2i Texture Analyzer (Stable Micro Systems, UK) with $5 \mathrm{~N}$ load cell and following ASTM D1621-10 ${ }^{1}$ with non-standard specimen sizes (12.7 $\mathrm{mm}$ diameter, $10 \mathrm{~mm}$ height). Specimens were deformed at a displacement rate of $0.5 \mathrm{~mm} \mathrm{~s}^{-1}$, within the linear elastic range (approximately $0.6 \mathrm{~mm}$ displacement). The elastic modulus of each sample was calculated as the slope of the stressstrain plot in the linear portion of the curve.

Statistical Analysis

Statistical analysis was performed using SPSS software (Version 22, IBM, USA). Homogeneity of variance and normality tests were performed prior to statistical analysis. For mass increase and mechanical properties one-way analysis of variance (ANOVA) was conducted with statistical significance at $p<0.05$. The analysis was followed by post hoc tests for pairwise comparisons using Tukey's honestly significant difference test. The coating thickness was analyzed using Kruskal-Wallis test, followed by the stepwise step-down multiple comparisons of means. All remaining dependencies were analyzed using the independent sample t-tests or Mann-Whitney tests.

\section{Density of Nanocomposite Coatings}

Glass microscope slides were cut into $30 \mathrm{~mm}$ x $13 \mathrm{~mm}$ rectangular sections. These planar glass substrates were deposited with 60 quadlayer coatings under the same LbL assembly conditions as foam templates, described above. The mean thickness of the coatings on planar substrates was 
$16.07 \pm 6.96 \mu \mathrm{m}$ based on 150 measurements from SEM micrographs taken at different locations (similar to the $14.77 \pm 5.49 \mu \mathrm{m}$ thickness of 60 quadlayer coatings observed on foams), and the density was calculated using the mean mass increase of $4.49 \pm 0.53 \mathrm{mg}$.

\section{Elastic Modulus of Nanocomposite Coating}

Silicone films $254 \mu \mathrm{m}$ thick were purchased from Specialty Manufacturing Inc. (USA) and cut into dogbone-shaped specimens with geometries conforming to ASTM D $635 .{ }^{2}$ Silicone dogbone specimens were deposited with 60 quadlayer coatings under the same LbL assembly conditions as foam templates, described above. Five uncoated silicone specimens and five specimens coated with 60 quadlayers were subjected to tensile testing using a Lloyds Materials Testing machine (Lloyds Instruments, UK) with a $50 \mathrm{~N}$ load cell at a displacement rate of $10 \mathrm{~mm} \mathrm{~min}^{-1}$. The strain in the coating was measured optically using a Vic-3D 7 digital image correlation system (Correlated Solutions Inc., USA). The elastic moduli of uncoated and coated specimens were calculated from the slope of the stress-strain curves in the linear portion of the curve, and are given in Table S1. The elastic modulus of the nanocomposite coating material was calculated based on a one-dimensional (1-D) rule of mixtures theory, ${ }^{3}$ in which the coated specimen was modeled as the composite material system shown in Figure $\mathbf{S 2}$ and assuming a perfect bond at the interface. The thickness of the coating and the elastic moduli of the uncoated and coated silicone films were used to calculate the elastic modulus of the coating, which are given in Table S1. All measurements were conducted in the ambient temperature. 
Table S1. Mean elastic moduli and standard deviations measured for uncoated silicone film $(n=5)$ and silicone coated with 60 quadlayers $(n=5)$, and calculated for the coating.

\begin{tabular}{llll}
\hline & $\begin{array}{l}\text { Uncoated } \\
\text { silicone film }\end{array}$ & $\begin{array}{l}\text { Coated } \\
\text { silicone film }\end{array}$ & Coating \\
\hline $\begin{array}{l}\text { Elastic } \\
\text { modulus }[\mathrm{MPa}]\end{array}$ & $0.393 \pm 0.044$ & $55.8 \pm 43.6$ & $601 \pm 518$ \\
\hline
\end{tabular}

\begin{tabular}{|c|}
\hline COATING \\
\hline SILICONE SUBSTRATE \\
\hline COATING \\
\hline
\end{tabular}

Figure S2. Schematic the coating-silicone substrate composite material system used to calculate the elastic modulus of the coating based on a 1-D rule of mixtures.

Cellulose acetate (CA) was purchased from Sigma Aldrich, UK, and dissolved in acetone to obtain a $1 \mathrm{wt} \%$ solution, which was cast onto glass microscope slides and dried using compressed air. These planar substrates were deposited with 60 quadlayer coatings under the same LbL assembly conditions as foam templates, described above. The coatings were delaminated from glass substrates with a sharp razor blade, and the layer of CA was removed by washing the detached coatings with acetone and DI water (as utilized previously for PEI/PAA materials $\mathrm{s}^{4,5}$ ). The stand-alone films of nanocomposite coating material were subjected to tensile testing using a Lloyds Materials Testing machine (Lloyds Instruments, UK) with a $50 \mathrm{~N}$ load cell at a displacement rate of $1.5 \mathrm{~mm} \mathrm{~min}^{-1}$. The elastic modulus of the nanocomposite coating material was calculated from the slope of the stress-strain curves in the linear region, yielding an 
average value of $1.67 \pm 1.06 \mathrm{GPa}(n=5)$. A representative stress-strain curve is shown in Figure S3. Cross-sectional SEM images of detached films (Figure S4) were used to measure sample thickness after testing, and confirmed the expected multilayer structure.

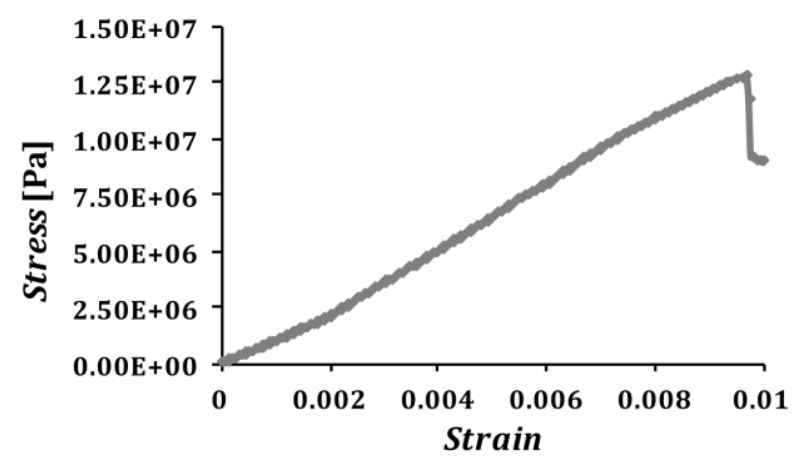

Figure S3. Representative stress-strain curve for detached films of the nanocomposite coating material loaded in tension.

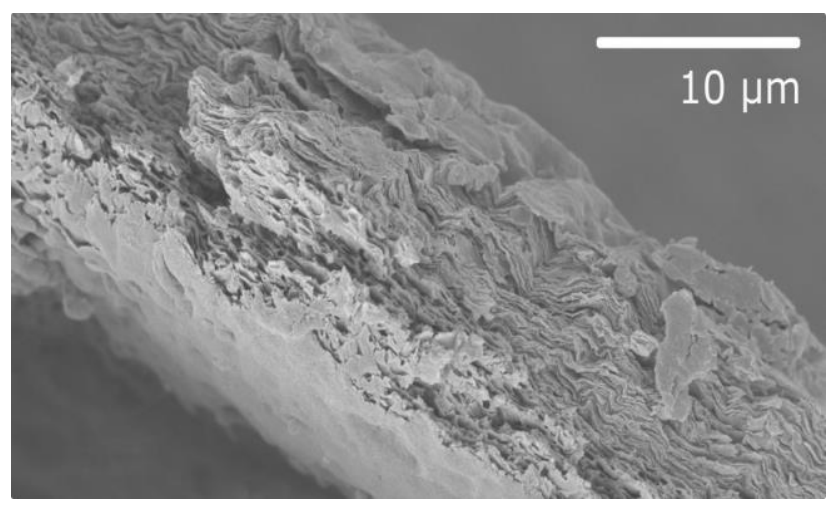

Figure S4. Representative micrograph of detached nanocomposite coating material in crosssection, following tensile testing. 


\section{REFERENCES}

[1] ASTM Standards D1621-10, Standard Test Method for Compressive Properties of Rigid Cellular Plastics. West Conshohocken, PA: ASTM International, 2010

[2] ASTM Standards D638-1, Standard Test Method for Tensile Properties of Plastics. West Conshohocken, PA: ASTM International, 2001

[3] Chen, X.; Kirsch, B. L.; Senter, R.; Tolbert, S. H.; Gupta, V. Tensile Testing of Thin Films Supported on Compliant Substrates. Mech. Mater. 2009, 41, 839-848.

[4] Mamedov, A. A.; Kotov, N. A. Free-Standing Layer-by-Layer Assembled Films of Magnetite Nanoparticles. Langmuir 2000, 16, 5530-5533.

[5] Mamedov A. A.; Kotov, N. A.; Prato, M.; Guildi, D. M.; Wicksted, J. P.; Hirsch, A. Molecular Design of Strong Single-Wall Carbon Nanotube/Polyelectrolyte Multilayer Composites. Nat. Mater. 2002, 1, 190-194. 